\title{
Social Ties and Susceptibility to the Common Cold
}

\author{
Sheldon Cohen, PhD; William J. Doyle, PhD; David P. Skoner, MD; Bruce \\ S. Rabin, MD, PhD; Jack M. Gwaltney, Jr, MD
}

Objective.-To examine the hypothesis that diverse ties to friends, family, work, and community are associated with increased host resistance to infection.

Design.-After reporting the extent of participation in 12 types of social ties (eg, spouse, parent, friend, workmate, member of social group), subjects were given nasal drops containing 1 of 2 rhinoviruses and monitored for the development of a common cold.

Setting.-Quarantine.

Participants,-A total of 276 healthy volunteers, aged 18 to 55 years, neither seropositive for human immunodeficiency virus nor pregnant.

Outcome Measures.-Colds (illness in the presence of a verified infection), mucus production, mucociliary clearance function, and amount of viral replication.

Results.- In response to both viruses, those with more types of social ties were less susceptible to common colds, produced less mucus, were more effective in ciliary clearance of their nasal passages, and shed less virus. These relationships were unaltered by statistical controls for prechallenge virus-specific antibody, virus type, age, sex, season, body mass index, education, and race. Susceptibility to colds decreased in a dose-response manner with increased diversity of the social network. There was an adjusted relative risk of 4.2 comparing persons with fewest (1 to 3 ) to those with most ( 6 or more) types of social ties. Although smoking, poor sleep quality, alcohol abstinence, low dietary intake of vitamin C, elevated catecholamine levels, and being introverted were all associated with greater susceptibility to colds, they could only partially account for the relation between social network diversity and incidence of colds.

Conclusions.-More diverse social networks were associated with greater resistance to upper respiratory illness.

THE HYPOTHESIS that multiple ties to friends, family, work, and community are beneficial in terms of physical health has gained substantial support over the last decade. Particularly provocative is epidemiologic evidence that those who participate in more diversified social networks - for example, are married, interact with family members, friends, neighbors, and fellow workers, and belong to social and religious groups-live longer than their counterparts with fewer types of social relationships. ${ }^{1,3}$ This association has been reported in multiple prospective studies, ${ }^{1,3}$ and the relative risk for mortality among those with less diverse networks is comparable in magnitude to

From the Department of Psychology, Carnegie MelIon University, Pittsburgh, $\mathrm{Pa}$ (Dr Cohen); Departments of Otolaryngology (Dr Doyle) and Pediatrics (Dr Skoner), Children's Hospital of Pittsburgh and the University of Pittsburgh School of Medicine, Pittsburgh, Pa; Department of Pathology, University of Pittsburgh School of Medicine (Dr Rabin); and Department of Internal Medicine, University of Virginia Health Sciences Center, Charlottesville (Dr Gwaltney).

Reprints: Sheldon Cohen, PhD, Department of Psychology, Carnegie Mellon University, Pittsburgh, PA 15213 (e-mail: $\underline{\text { SCOHEN@CMU.EDU). }}$ the relation between smoking and mortality from all causes. ${ }^{3}$ Unfortunately, the behavioral and biological characteristics that link social networks of greater scope to longevity have not been identified. However, evidence implicating social network ties in the regulation of the immune system suggests that social networks may play a role in the ability of the host to resist infection., ${ }^{4,5}$

We report a prospective study assessing the role of social network diversity in susceptibility to upper respiratory that infections. In theory, participation in a more diverse social network may influence the motivation to care for oneself by promoting feelings of self-worth, responsibility, control, and meaning in life ${ }^{6,7}$ This motivation would be manifest in an increase in health promoting behaviors such as abstaining from smoking, moderating alcohol consumption, and improving diet, exercise regimens, and sleep quality. ${ }^{78}$ Greater network diversity has also been related to less anxiety, depression, and nonspecific psychological distress. ${ }^{9}$ Lower levels of these negative mood states have been associated with lower basal levels of epinephrine, norepinephrine, and Cortisol. ${ }^{10}$ In turn, these hormones are thought to influence both cellular and humoral immune function and potentially to alter host resistance to infection. ${ }^{1112}$

Although there is evidence for increased susceptibility to common colds among smokers ${ }^{13}$ and decreased risk among moderate drinkers, ${ }^{13}$ little is known about the role of other health practices or about levels of catecholamines, Cortisol, or normal variations in cellular immune function in susceptibility to the common cold. ${ }^{14}$ The study reported Here examines the importance of network diversity for susceptibility, the importance of these behavioral and biological markers for susceptibility, and the possible role that these markers might play in linking social network diversity to colds.

\section{METHODS \\ Subjects}

The subjects were 125 men and 151 women from the Pittsburgh, Pa, area who responded to newspaper advertisements and were judged to be in good health after a medical examination. Their ages ranged from 18 to 55 years. They were studied in 6 groups (4 in the spring and 2 in the fall) with 40 to 60 subjects in each. Subjects were paid $\$ 800$ for their participation. The study was approved by the institutional review boards of Carnegie Mellon University, University of Pittsburgh, and Children's Hospital of Pittsburgh, and informed consent was obtained from each subject after the nature and possible consequences of the study were fully explained.

\section{Experimental Plan}

All volunteers came to the hospital for medical eligibility screenings. They were not accepted into the study if they had previous nasal or otologic surgery; a history of asthma or cardiovascular disorders; abnormal clinical profiles on urinalysis, complete blood cell count, blood enzymes, or any of 3 nutritional markers (albumin, transferrin, or retinol binding protein); or were pregnant or currently lactating, seropositive for human immunodeficiency virus, or on a regular medication regimen. Social networks, health practices (except diet), age, education, 
race, sex, and body weight and height were also assessed at the screening and used as baseline data for those who were deemed eligible.

Eligible subjects returned to the hospital both 4 and 5 weeks after screening to have blood drawn for assessment of natural killer (NK) cell activity (based on both blood draws) and antibody to the challenge virus (based on the second blood draw). A personality questionnaire was administered twice, once at each blood draw.

Subjects were quarantined within 1 week following the second blood draw. During the first 24 hours of quarantine (before viral exposure), they received a nasal examination. They were excluded from the study at this point if a nasal wash culture indicated they were infected by a rhinovirus; the nasal examination showed congestion, mucosal edema, or nasal discharge; or they reported symptomatic upper respiratory tract infections within the 30 days before quarantine. Baseline respiratory symptoms, nasal mucociliary clearance, and nasal mucus production were assessed at this time. Urine samples for endocrine assessment and information on dietary intake were also collected.

At the end of the first 24 hours of quarantine, subjects were given nasal drops containing a low infectious close (100-300 tissue culture infectious close $\left(\mathrm{TCID}_{50}\right) /$ $\mathrm{mL}$ ) of 1 of 2 types of rhinovirus-RV39 $(n=147)$ or Hanks $(n=129)$. Two viruses were used to assess whether predictors of susceptibility are equivalent across different rhinovirus types. Rhinovirus type R V39 was used in the first 3 groups of subjects and rhinovirus strain Hanks in the last 3.

The quarantine continued for 5 days after exposure. During this period, the subjects were housed individually but were allowed to interact with each other at a distance of $3 \mathrm{ft}$ or more. Nasal secretion samples for virus culture were collected on each of the 5 days. Subjects were also tested on each day for respiratory symptoms, nasal mucociliary clearance, and nasal mucus production with the same procedures as used at baseline. Approximately 28 days after challenge, another blood sample was collected for serological testing. All investigators were blinded to subjects' status on social network, personality, endocrine, health practice, immune, and prechallenge antibody measures.

\section{Standard Control Variables}

We used 8 control variables that might provide alternative explanations for the relation between network diversity and illness. Prechallenge antibody titer was categorized into approximate quartiles: less than 2,2 to 4,8 to 16 , and greater than
16. Age and body mass index (weight in kilograms divided by the square of height in meters) were scored as continuous variables. Whether the trial was conducted in the fall (November) or spring (April and May), race (white [81.2\%] or not [18.8\%]), sex, and viral type (RV39 or Hanks) were scored as clichotomous variables. Education levels were categorized as high school graduate or less, some college, and bachelor's degree or greater.

\section{Social Network Diversity}

The Social Network Index assesses participation in 12 types of social relationships. ${ }^{15}$ These include relationships with a spouse, parents, parents-in-law, children, other close family members, close neighbors, friends, workmates, schoolmates, fellow volunteers (eg, charity or community work), members of groups without religious affiliations (eg, social, recreational, or professional), and members of religious groups. One point is assigned for each type of relationship (possible score of 12) for which respondents indicate that they speak (in person or on the phone) to someone in that relationship at least once every 2 weeks. The total number of persons with whom they speak at least once every 2 weeks (number of network members) was also assessed.

\section{Pathways Linking Social Networks to Susceptibility}

Health practices and markers of endocrine and immune function were assessed before viral challenge as possible pathways linking network diversity to susceptibility. Smokers were defined as those smoking cigarettes, cigars, or a pipe on a daily basis. ${ }^{13}$ In calculating the average number of alcoholic drinks per day, a bottle or can of beer, a glass of wine, or a shot of spirits were each treated as a single drink. ${ }^{13}$ Exercise was assessed by a question asking the number of times per week that the subject engaged in an activity long enough to work up a sweat, get the heart thumping, or become out of breath. ${ }^{10}$ Quality of sleep was assessed by scales assessing subjective sleep quality, sleep latency, disturbance, and efficiency (percentage of time in bed sleeping). ${ }^{17}$ Dietary intake of vitamin $\mathrm{C}$ and zinc was also assessed by standard questionnaire. ${ }^{18}$ Analyses including diet variables are limited to 228 subjects who completed the questionnaire according to standard criteria. $^{10}$

Epinephrine, norepinephrine, and Cortisol levels were assessed as markers of stress. ${ }^{10}$ These hormones were measured in 24-hour urine samples collected just prior to viral challenge. High-performance liquid chromatography with electrochemical detection was used for measurement of the urinary catecholamines.
Urinary Cortisol assays were performed by a double-antibody competitive radioimmunoassay.

Natural killer cell activity is thought to play an important role in limiting viral replication. ${ }^{20}$ We conducted a whole blood NK assay. ${ }^{21}$ The results of the 2 blood draws were averaged to estimate cytotoxicity.

\section{Personality as an Alternative \\ Explanation}

We examined personality factors that might account for both greater network diversity and less susceptibility. We assessed the "Big-Five". characteristics thought to represent the basic structure of personality. ${ }^{22}$ These factors are commonly described as extraversion, agreeableness, conscientiousness, emotional stability, and openness. To assess the Big-Five, we used a modified version of Goldberg's $^{22}$ adjective scales. Our version includes 50 adjectives, 10 for each factor. We used the average of the scores from the 2 administrations of the scales.

\section{Viral Cultures and Antibody Response}

Nasal washes were cultured for virus, and all positive specimens were quantitated. $^{23}$ Neutralizing antibody to the challenge virus was measured in serum collected before and 28 days after exposure to the challenge virus. ${ }^{23}$ Serum antibody titers are reported as reciprocals of the initial dilution of serum.

\section{Signs and Symptoms}

At the end of each day of quarantine, subjects rated the severity of 8 respiratory symptoms (congestion, runny nose, sneezing, cough, sore throat, malaise, headache, and chills) during the previous 24 hours. $^{2-1}$ Ratings ranged from 0 (none) to 4 (very severe) for each symptom. The symptom scores were summed within each day. The score for the day before challenge was subtracted from each daily score after viral challenge. The adjusted postehallenge symptom scores were summed to create an adjusted total symptom score. Subjects were also asked each day if they had a cold.

Mucus production was assessed by collecting used tissues in sealed plastic bags. ${ }^{25}$ The bags were weighed and the weight of the tissues and bags subtracted. To adjust for baseline, weight on the day before challenge was subtracted from each daily weight after viral challenge. The adjusted postehallenge weights were summed to create an adjusted total mucus weight score.

Nasal mucociliary clearance function refers to the effectiveness of nasal cilia in clearing-mucus from the nasal passage toward the nasopharynx. Clearance function is assessed as the time required 


\begin{tabular}{|c|c|c|c|c|c|c|}
\hline \multirow[b]{2}{*}{$\begin{array}{l}\text { Prechallenge } \\
\text { Antibody } \\
\text { Titer }\end{array}$} & \multirow[b]{2}{*}{ Virus Type } & \multirow[b]{2}{*}{$\begin{array}{c}\text { Challenge, } \\
\text { No. }\end{array}$} & \multirow[b]{2}{*}{$\begin{array}{l}\text { Infection, } \\
\% \text { (No.) }\end{array}$} & \multirow[b]{2}{*}{$\begin{array}{l}\text { Objective } \\
\text { Criterion, \% } \\
\text { (No.) }\end{array}$} & \multirow[b]{2}{*}{$\begin{array}{c}\text { Self-reported } \\
\text { Criterion, \% } \\
\text { (No.) }\end{array}$} & \multirow[b]{2}{*}{$\begin{array}{r}1 \\
\text { Jackson } \\
\text { Criterion, } \\
\% \text { (No.) }\end{array}$} \\
\hline & & & & & & \\
\hline \multirow[t]{3}{*}{$\leq 2$} & RV39 & 71 & $99(70)$ & $63(45)$ & $55(39)$ & $59(42)$ \\
\hline & Hanks & 73 & $99(72)$ & $53(39)$ & $52(38)$ & $56(41)$ \\
\hline & Total & 144 & $99(142)$ & $58(84)$ & $54(77)$ & $58(83)$ \\
\hline \multirow[t]{3}{*}{$\geq 4$} & RV39 & 76 & $82(62)$ & $25(19)$ & $29(22)$ & $24(18)$ \\
\hline & Hanks & 56 & $52(29)$ & $11(6)$ & $11(6)$ & $16(9)$ \\
\hline & Total & 132 & $69(91)$ & 19(25) & $21(28)$ & $21(27)$ \\
\hline
\end{tabular}

for a dye administered in the nostrils to reach the nasopharynx. ${ }^{26}$ Each daily time was adjusted (by subtracting) for baseline, and the adjusted average time in minutes was calculated across the postchallenge days of the trial.

\section{Infections and Colds}

Volunteers were considered to have a cold if they both were infected and met illness criteria. They were classified as infected if the challenge virus was isolated on any of the 5 postchallenge study days or there was a 4-fold or greater rise in viral-specific serum neutralizing antibody titer from before exposure to 28 days after exposure. We examined colds using 3 different illness criteria. The illness criterion used in the primary analyses was based on objective indicators of illness-a total adjusted mucus weight of at least 10 g or adjusted average mucociliary nasal clearance time of at least 7 minutes. The mean $( \pm S D)$ total adjusted respiratory symptom score for those with colds defined as infection plus the objective illness criterion was $19.28( \pm 14.7)$ vs $5.67( \pm 8.1)$ for those without colds $(\mathrm{t}[274]=-9.88$; $\mathrm{P}<.001)$. The 2 other illness criteria we used in defining colds were based on subject self-report. The first required subjects reporting (using their own definition) having a "cold." The second, the modified Jackson criterion, is previously validated and requires a total adjusted symptom score of 6 or more in addition to either reporting having a cold or reporting rhinorrhea on 3 or more days of the trial. $^{17}$

\section{Statistical Analyses}

We used stepwise logistic regression to predict the binary outcome incidence of a cold ${ }^{26}$ and multiple linear regression to predict continuous outcomes. ${ }^{29}$ Social network diversity was initially treated as a continuous variable. In these cases, we report the regression coefficient for network diversity, its SE, and probability level. However, to provide an estimate of relative.risk, we also present odds ratios (ORs) and 95\% confidence intervals (CIs) based on network diversity categorized into low (1-3 types of relationships), moderate (4-5 types), and high (s6 types). We sequentially added variables to the first step of regression analyses to determine whether the association between network diversity (entered alone in the second step) and susceptibility to colds is substantially reduced after controlling for the contribution of other variables. Finally, when we report mean levels of continuous outcomes, we also report the SEM.

\section{RESULTS}

Rates of infections and colds stratified by prechallenge serostatus are presented in Table 1. Rates of colds were similar for the objective, self-reported cold, and Jackson illness criteria. The greater protective effects of antibody for rhinovirus strain Hanks is a new observation.

\section{Standard Controls and Susceptibility}

When examined as an individual pre-, clictor, increasing prechallenge antibody was associated with decreased incidence of colds (objective criterion for illness, $\mathrm{P}<.001)$. Education was also associated with incidence in an unexpected manner. The highest rate of colds was associated with those with high school degrees or less (52\%), the next highest with those with college degrees or more (45\%), and the lowest with those with some college (33\%, $\mathrm{P}=.04)$. Other standard control variables were not individually associated with the incidence of colds. When the 8 standard controls were entered into the regression simultaneously to test the independent contribution of each control variable, associations with antibody titers $(\mathrm{P}<.001)$ and education $(\mathrm{P}=.04)$ remained the same. In addition, increasing age was associated with increased incidence $(\mathrm{P}=.03)$, as was being exposed to rhinovirus type 39 (44\% colds) as opposed to rhinovirus strain Hanks (35\% colds; $\mathrm{P}=.03)$.

\section{Social Networks and Susceptibility}

As apparent from the Figure, when we used the objective illness criterion, the rate of colds decreased with increased social network diversity $( \pm \mathrm{SE})(\mathrm{b}=-0.19$ $[ \pm 0.08] ; \mathrm{P}=.01$ for continuous variable; OR, 3.0 [95\% CI, 1.23-7.44] for low, 1.5 [95\% CI, 0.87-2.46] for moderate, and 1.0 for high social network diversity). Enter- ing the standard control variables into the equation before social network diversity strengthened this association $(b=-0.29$ [ \pm 10 ], $\mathrm{P}=.01$; adjusted OR, 4.2 [95\% CI, 1.34-13.29] for low, 1.9 [95\%CI, 1.00-3.51] for moderate, and 1.0 for high), There were no interactions between the standard control variables and social network diversity in predicting colds. Hence, the relationships were similar for the 2 virus types, for different levels of serologic status, age, sex, race, education, and body mass index, and across the 2 seasons. Of special note for interpretation of our data is that network diversity and rates of colds are similarly associated across virus types and across prechallenge seropositives and seronegatives (Table 2).

Use of the self-reported cold criterion for illness resulted in adjusted ORs similar to those found with the objective illness criterion (adjusted OR, 3.5 [95\% CI, 1.18-10.20] for low, 1.9 [95\% CI, 1.023.50] for moderate, and 1.0 for high social network diversity groups) (Figure). In the case of the modified Jackson criterion, there was no graded association between network diversity and colds but a difference between the low and high network diversity groups (adjusted OR, 3.2 [95\% CI, 1.04-9.77], 1.2 [95\% CI, 0.662.26], and 1.0) (Figure). In later analyses, we use the objective criterion in defining colds because this measure of illness is not subject to biases in subjects' symptom reporting.

We also examined whether social network diversity was associated with continuous measures of the 2 objective signs of illness among infected people. Both analyses were adjusted for standard control variables. Increases in network diversity were associated with decreases in mucus weights (mean, $0.95[ \pm 0.18]$ $\log _{10}$ grams for low, 0.73 [ \pm 0.07$]$ for moderate, and $0.66[ \pm 0.05]$ for high diversity; $F[1,216]=7.65 ; \mathrm{P}=.007$ ) and increases in mucociliary clearance function (mean, $6.3[ \pm 1.4]$ minutes for low, 5.0 $[ \pm 0.6]$ for moderate, and $3.6[ \pm 0.4]$ for high diversity; $\mathrm{F}[1,218]=5.75 ; \mathrm{P}=.02$ ).

In contrast to the diversity of the network, the total number of networkmembers was not associated with colds $(\mathrm{P}=.12)$. Moreover, entering the number 


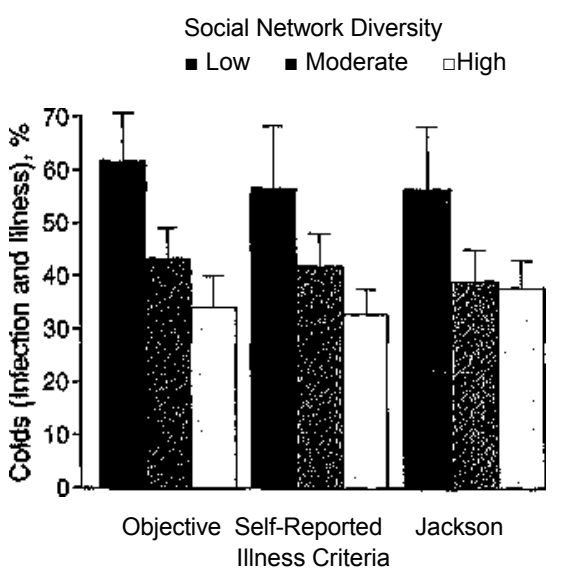

Observed incidence of colds by social network diversity using 3 illness criteria. Low diversity is defined as 1 to 3 types of social relationships; moderate, 4 to 5; and high, 6 or more. Error bars indicate SEs.

of network members into the first step of the regression equation along with standard controls did not reduce the association between diversity and colds ( $\mathrm{b}=-0.36[ \pm 0.13] ; \mathrm{P}=.01)$.

\section{Social Networks and the Quantity of Viral Replication}

Because greater replication of virus during the 5 days following exposure was associated with greater likelihood of developing a cold $(\mathrm{b}=1.04[ \pm 0.18], \mathrm{P}<.001$ for all subjects; $b=0.93[ \pm 0.19], P<.001$ for infected subjects), we thought it might account for the relations between social network diversity and colds. Viral replication as measured by viral concentration in nasal washes decreased with increases in network diversity (adjusted for standard controls, $\mathrm{F}[\mathrm{l}, 263]=5.76 ; \mathrm{P}=.02$; for all subjects: mean, $2.23[ \pm 0.30]$ login titers for low, $1.74[ \pm 0.12]$ for moderate, and $1.51[ \pm 0.10]$ for high; F[l, 220] $=6.19$; $\mathrm{P}=.02$; for infected subjects: mean, 2.57 [ \pm 0.28$]$ logio titers for low, $2.00[ \pm 0.12]$ for moderate, and $1.83[ \pm 0.10]$ for high). However, the association between network diversity and the incidence of colds was only slightly reduced when quantity of viral replication was added as a control variable $(b=-0.24[ \pm 0.11], P=.03$ for all subjects; $\mathrm{b}=-0.25[ \pm 0.10], \mathrm{P}=.02$ for infected subjects; without viral replication in the equation, $\mathrm{b}=-0.29[+0.10], \mathrm{P}=.01$ for both infected and all subjects). Overall, these analyses suggest that the relationship between social network diversity and colds was not primarily mediated by quantity of viral replication.

\section{Pathways Linking Social Networks to Susceptibility}

We began by testing whether each of the proposed health behavior endocrine and immune pathways was associated
Table 2.--Rates and Numbers of Persons With Colds by Number of Types of Social Relationships, Stratified by Preohallenge Antibody Titer and Virus*

\begin{tabular}{|c|c|c|c|}
\hline \multirow[b]{2}{*}{ Preohallenge } & & \multicolumn{2}{|c|}{$\begin{array}{l}\text { Number of Types of } \\
\text { Social Relationships }\end{array}$} \\
\hline & & $1-5$, & $\geq 6$ \\
\hline Antibody & Virus & No. (\%) & No. (\%) \\
\hline Titer & Type & With Colds & With Colds \\
\hline \multirow[t]{3}{*}{$\leq 2$} & RV39 & $25 / 33(76)$ & $20 / 38(53)$ \\
\hline & Hanks & $18 / 30(60)$ & 21/43 (49) \\
\hline & Total & $43 / 63(68)$ & 41/81 (51) \\
\hline \multirow[t]{3}{*}{$\geq 4$} & RV39 & 11/34 (32) & 8/42(19) \\
\hline & Hanks & $3 / 26(12)$ & $3 / 30(10)$ \\
\hline & Total & 14/60(23) & $11 / 72(15)$ \\
\hline
\end{tabular}

"Low and moderate levels of social diversity have been combined Into 1 category (1-5) so that there are a sufficient number of persons within each cell to provide a reliable estimate of the rates of colds.

with susceptibility to colds. Each was tested individually and then simultaneously with other measures in their category (eg, smoking independent of other health practices). In all cases, the standard control variables were entered in the first step of the regression, and the variables representing the proposed pathway were entered in the second step. Table 3 presents these data for factors that were individually associated with colds.

Smokers, persons exercising 2 times or fewer a week, those with sleep efficiency of 0.80 or less, those drinking 1 drink or fewer per day, and those ingesting $85 \mathrm{mg}$ or fewer of vitamin $\mathrm{C}$ a day were all at greater risk for developing colds. There were no associations between zinc and colds or between the other sleep measures and colds. When the health practices that were individually associated with colds were entered into the regression simultaneously, smoking, drinking 1 drink or fewer per day, and sleep efficiency all made independent contributions.

Persons with levels of norepinephrine above the median level $(175 \mathrm{nmol} / \mathrm{cl})$ were at greater risk for developing colds than those below the median. A similar but weaker relation was found for epinephrine (median, $21 \mathrm{nmol} / \mathrm{d}$ ). Neither Cortisol levels nor NK cell cytotoxicity was associated with colds. When epinephrine and norepinephrine were entered into the equation simultaneously, the contributions of both were attenuated.

We then conducted a series of logistic regressions to determine whether social network diversity was associated with each of the health practice and endocrine factors that we determined to be risks for colds. All analyses included the standard control variables. Lower levels of network diversity were associated with being a smoker $(\mathrm{b}=-0.22[ \pm 0.09], \mathrm{P}=.02)$ and with insufficient exercise $(b=-0.28[ \pm 0.08]$, $\mathrm{P}=.01$ ). However, network diversity was not associated with alcohol consumption, dietary intake of vitamin C, or sleep efficiency or with above-median levels of epinephrine or norepinephrine.
Table 3.-Adjusted Odds Ratios (95\% Confidence Intervals) for Health Practices and Endocrine Measures Associated With the Incidence of Colds *

\begin{tabular}{lll}
\hline & \multicolumn{2}{c}{$\begin{array}{c}\text { Potential Mediators } \\
\text { Entered in Equation }\end{array}$} \\
\cline { 2 - 3 } & Individually & $\begin{array}{l}\text { With } \\
\text { Others }\end{array}$ \\
\hline $\begin{array}{l}\text { Health practices } \\
\text { Smoking }\end{array}$ & $3.0(1.5-6.1)$ & $3.3(1.5-7.0)$ \\
\hline $\begin{array}{l}\text { Exercising } \leq 2 \\
\text { times/wk }\end{array}$ & $1.8(1.0-3.2)$ & $1.5(0.8-2.7)$ \\
\hline $\begin{array}{l}\text { Sleep efficiency of } \\
\leq 0.80\end{array}$ & $2.6(1.2-5.8)$ & $2.8(1.2-4.8)$ \\
\hline $\begin{array}{l}\text { Drinking } \leq 1 \\
\text { drink/d }\end{array}$ & $2.0(1.0-3.8)$ & $2.6(1.3-5.3)$ \\
\hline $\begin{array}{l}\text { Ingesting } \leq 0.85 \text { mg } \\
\text { vitamin C/d }\end{array}$ & $2.0(1.0-3.8) \dagger$ & \\
\hline $\begin{array}{l}\text { Endocrine measures } \\
\text { Norepinephrine }\end{array}$ & $1.9(1.0-3.5)$ & $1.7(0.9-3.2)$ \\
\hline Epinephrine & $1.8(0.9-3.6)$ & $1.5(0.8-3.1)$ \\
\hline
\end{tabular}

*Odds ratios are adjusted for standard control variables. Separate regressions were fit to examine the association of each Individual mediator with colds and a single regression was fit to examine the association of each mediator independent of other variables in its group (simultaneous entry).

†The table Is based on the entire sample for all but vitamin C, which is based on the subsample who completed diet questionnaires $(n=228)$.

$\ddagger$ Analyses of the subsample, controlling for vitamin $C$ intake as well as the other health practices result in identical conclusions. In these analyses, diet is not related to colds after controlling for other health practices (odds ratio, 1.6; 95\% confidence Interval, 0.80-3.23).

Because smoking and exercise were associated with both social network diversity and with colds, they are the only proposed mediators that could operate as pathways linking network diversity to susceptibility. To determine whether these factors might operate as pathways, they were entered along with the standard controls in the first step of the regression equation, with network diversity entered in the second step. Addition of these health practices to the equation slightly decreased the association between social network diversity and susceptibility to colds ( $b=-0.24[ \pm 0.10], P=.02$ with smoking and exercise; $\mathrm{b}=-0.29[ \pm 0.10], \mathrm{P}=.01$ before adding smoking and exercise). Hence the health practices account for a small proportion of the relationship but do not act as primary pathways linking network diversity and colds in this study.

\section{Personality as an Alternative Explanation}

We entered each of the Big-Five personality factors into separate equations along with the standard controls predicting colds. Only extraversion was associated with susceptibility with those with low scores(introverts-below the median of 28.5) at greater risk for colds (adjusted OR, 2.7; 95\% CI, 1.45-4.92). Moreover, extraversion was associated with higher levels of social network diversity $(b=0.25$ [ \pm .08$], \mathrm{P}=.01)$. However, adding extraversion to the regression equation including standard controls does not substan- 
tially alter the relation between network diversity and incidence of colds $(b=-0.24$ $[ \pm 0.10], \mathrm{P}=.02$ with extraversion; $\mathrm{b}=-0.29$ $[ \pm 0.10], \mathrm{P}=.01$ without extraversion).

\section{COMMENT}

The results indicate people who participate in more types of social relationships have less susceptibility to rhinovirus-induced colds. This association is graded, although the risk increases most among those with the fewest types of relationships. Moreover, the adjusted OR is substantial, with those reporting 1 to 3 types of relationships having more than 4 times the risk of those reporting 6 or more types of relationships. The association between network diversity and susceptibility held even after controlling for the number of people in the social network indicating that it is diversity of the network (having multiple types of relationships) that matters not the sheer number of network members.

Although the quantity of viral replication decreased with increased network diversity, the quantity of replication did not act as a primary pathway linking network diversity and the development of colds. These results suggest that social network diversity may be associated with more than 1 disease process, ie, extent of viral replication and a process or processes that modulate the production of signs and symptoms of illness.

Several health practices and endocrine measures were associated with risk for colds, including replications of previously established risks of smoking, ${ }^{13}$ as well as benefits of moderate alcohol consumption. ${ }^{13}$ Although not previously reported, the elevated risk associated with high basal levels of catecholamines is consistent with previous reports of an association between psychological stress and increased susceptibility. ${ }^{2,20}$ We also found new evidence for increased risk among those exercising 2 times or fewer a week and among those with sleep efficiencies lower than 0.80 . Intake of vitamin $\mathrm{C}$ below $85 \mathrm{mg} / \mathrm{d}$ (this cutoff was empirically derived) were also associated with greater risk, but additional intake was not beneficial. The relative risks associated with health practices ranged from 1.8 to 3.0 , while the relative risk associated with elevated catecholamines ranged from 1.8 to 1.9. However, only smoking and exercise met the criteria for pathways linking social network diversity to susceptibility, and together these could account for only a part of this relation. Finally, the personality characteristic extraversion was examined as a factor that might account for increases in network diversity and decreases in susceptibility. Although those with low scores (introverts) had less diverse networks and were at greater risk for colds, this variable was unable to account for the relation between social network diversity and susceptibility.

We can only speculate on what other mechanisms might mediate the association of network diversity and colds. Our data suggest eliminating a number of possibilities. At least for seronegative subjects, the relation was attributable to increased illness among infected persons (99\% were infected) and not increased incidence of infection. The similarity of the association across serostatus also suggests that the mechanism is not primarily mediated by serum antibody production in response to the virus among those previously exposed. In addition, we found little evidence for the role of NK cell activity. However, other characteristics of immune status may operate as pathways. For example, there may be behavioral effects on the release of cytokines in the nasal passage that effect the triggering of symptoms. ${ }^{80}$

A relation between network diversity and host resistance may provide a partial explanation for the association between social network diversity and allcause mortality. Unfortunately, without a better understanding of the underlying mechanisms linking network diversity to colds, we cannot say whether our data have implication for host resistance to other infectious agents that may cause or contribute to mortality.

This study was supported by a grant from the National Institute of Mental Health (MH50429), a Research Scientist Development Award to Dr Cohen from the National Institute of Mental Health (MH00721), a grant from the National Institute of Health to the University of Pittsburgh Medical Center General Clinical Research Center (NCRR/ GCRC 5M01 RR00056), and support from the Petzer Institute.

We are indebted to Janet Schlarb, James Seroky, the staff of the General Clinical Research Center, Theresa Whiteside, $\mathrm{PhD}$, and Robert McDonald, Jr, $\mathrm{MD}$, and their laboratory staffs, and the volunteers for their contributions to the research, and to Joel Greenhouse, $\mathrm{PhD}$, for statistical advice, and Kenneth Kotovsky, PhD, and Vicki Helgeson, $\mathrm{PhD}$, for comments on earlier drafts.

\section{References}

1. Berkman LF, Syme, SL. Social networks, host resistance, and mortality. Am J Epidemiol. 1979; 109:186-204.

2. Vogt TM, Mullooly JP, Ernst D, Pope CR, Hollis JP. Social networks as predictors of ischemic heart disease, cancer, stroke and hypertension. J Clin Epi demiol. 1992;45:659-666.

3. House JS, Landis KR, Umberson D. Social rela tionships and health. Science. 1988;241:540-545. 4. Uchino BN, Cacioppo JT, Kiecolt-Glaser JK. The relationship between social support and physiologi cal processes. Psychol Bull. 1996;119:488-531.

5. Kiecolt-Glaser JK, Malarkey WB, Cacioppo JT, Glaser R. Stressful personal relationships: immune and endocrine function. In: Glaser R, Kiecolt-Glaser J, eds. Handbook of Human Stress and Immunity. San Diego, Calif: Academic Press Inc; 1994:321-339. 6. Thoits PA. Multiple identities and psychological well-being. Am Social Rev. 1983;48:174-187.

7. Cohen S. Psychosocial models of the role of social support in the etiology of physical disease. Healtk Psychol. 1988;7:269-297.

8. Berkman LF, Breslow L. Health and Ways of Living: The Alameda County Study. New York, NY: Oxford University Press; 1983.

9. Cohen S, Wills TA. Stress, social support, and the buffering hypothesis. Psychol Bull 1985;98:310357.

10. Baum A, Grunberg N. Measurement of stress hormones. In: Cohen S, Kessler RC, Underwood Gordon L, eds. Measuring Stress. New York, NY: Oxford University Press; 1995:175-192.

11. Glaser R, Kiecolt-Glaser J, eds. Handbook of Human Stress and Immunity. San Diego, Calif: Academic Press Inc; 1994.

12. Ader R, Cohen N, Felton D, eds. Psyclioneuroimmunology. San Diego, Calif: Academic Press Inc; 1991

13. Cohen S, Tyrrell DAJ, Russell MAH, Jarvis MJ, Smith AP. Smoking, alcohol consumption, and sus ceptibility to the common cold. Am J Public. Heath. 1993;83:1277-1283.

14. Gwaltney JM Jr. Rhinoviruses. In: Evans AS, ed. Viral Infections of Humans: Epidemiology and Con trol. New York, NY: Plenum Publishing Corp; 1984, 15. Cohen S. Social supports and physical health. In: Greene AL, Cummings M, Karraker KH, eds. Life-Span Developmental Psychology: Perspectives ore Stress and Coping. Hillsdale, NJ: Erlbaum As sociates; 1991.

16. Paffenbarger RS Jr, Blair SN, Lee I, Hyde RT. Measurement of physical activity to assess health effects in free-living populations. Med Sci Sports Exerc. 1993;25:60-70.

17. Buysse DJ, Reynolds CF, Monk TH, Borman SR, Kupfer DJ. The Pittsburgh Sleep Quality In dex. Psychiatry Res. 1989;28:193-213.

18. Block G, Hartman AM, Naughton D. A reduced dietary questionnaire. Epidemiology. 1990;1:58-64,

19. Block G, Thompson FE, Hartman AM, Larkin FA, Guire KE. Comparison of two dietary ques tionnaires validated against multiple dietary records collected during a 1-year period. J Am Diet Assoc. 1992;92:686-693.

20. Whiteside TL, Bryant J, Day R, Herberman RB Natural killer cytotoxicity in the diagnosis of im mune dysfunction. J Clin Lab Anal. 1990;4:102-114. 21. Fletcher MA, Baron GC, Ashman MR, Fiscli! MA, Klimas NG. Use of whole blood methods in as sessment of immune parameters in immunode ficieney. Diagn Clin Immunol. 1987;5:68-91.

22. Goldberg LR. The development of markers for the Big-Five factor structure. Psychol Assess. 1992; 4:26-42.

23. Gwaltney JM Jr, Colonno RJ, Hamparian VV, Turner RB. Rhinovirus. In: Schmidt NJ, Emmons RW, eds. Diagnostic Procedures for Viral, Rickett sial, and Chlamydial Infections. 6th ed. Washing ton, DC: American Public Health Association; 1989: 579-614.

24. Farr BM, Gwaltney JM Jr, Hendley JO, et al. A randomized controlled trial of glucocorticoid pro phylaxis against experimental rhinovirus infection, J Infect Dis. 1990;162:1173-1177.

25. Doyle WJ, McBride TP, Swarts JD, Hayden FG, Gwaltney JM Jr. The response of the nasal airway, middle ear, and eustachian tube to provocative rhi novirus challenge. Am J Rhinol. 1988;2:149-154.

26. Hosmer DW Jr, Lemeshow S. Applied Logistic Regression. New York, NY: John Wiley \& Sons Inc; 1989.

27. Cohen J, CohenP. Applied Multiple Regression! Correlation Analysis for the Behavioral Sciences. Hillsdale, NJ: Erlbaum Associates, 1975.

28. Cohen S, Tyrrell DAJ, Smith AP. Psychological stress and susceptibility to the common cold. NEngl J Med. 1991;325:606-612.

29. Stone AA, Bovbjerg DH, Neale JM, Napoli A Valdimarsdottir H, Gwaltney JM Jr. Development of common cold symptoms following experimental ' rhinovirus infection is related to prior stressful life events. Behav Med. 1993;8:115-120.

30. Akira S, Kishimoto T. IL-6 and NF-ILG in acutephase response and viral infection. Immunol Rev. 1992;127:25-50. 